\title{
Theoretical and Empirical Research on Cultivating the core Competencies of the Enterprise
}

\author{
Bai Xiaotong ${ }^{1}$, Bi Ke ${ }^{1}$, Wang Xinyu ${ }^{1}$ \\ ${ }^{1}$ School of Economics and Management, Jiangsu University of Science and Technology \\ Zhenjiang, Jiangsu, China
}

\begin{abstract}
The core competence is the essence of the enterprise competition. This paper studies the cultivation of the enterprise's core competence. Using literature research methods and empirical research methods, we concluded the method of identifying core competences and their cultivation approaches. Then conducted empirical research on TCL color TV sets. The innovation is to improve the company's core competence cultivation theory.
\end{abstract}

Keywords-Enterprise; Core competencies; Cultivate; TCL color TV

\section{INTRODUCTION}

In 1990, the concept of 'core competence' was first proposed by c.k. Prahalad and Gary Hamel because they published the company core competence in the harvard business review. After that, 'core competence' as a lasting competitive advantage source gained wide attention and universal recognition in the field of theory and practice. In terms of theoretical research, the academic achievements of management in this field have been abundant in 20 years, but there is still room for improvement. Practical applications, the 2017 China top 500 enterprises analysis report pointed out that although China top 500 enterprises has a certain level of competitiveness competitive power, but there is still a huge gap compared with the world top 500 [1], It shows that domestic enterprises have not grasped the core of development because of overemphasizing the product diversification. Therefore, cultivate and improve the core competence has a long way for China's enterprises.

\section{THEORETICAL BASIS}

\section{A. Definition and characteristics of enterprise core competence}

Enterprise core competence refers to the ability of enterprises to allocate resources to maintain continuous competitive advantage. It includes two meanings: one refers to the ability of enterprises to acquire resources and transform them into necessary skills and products. Second refers to the ability of enterprises to mobilize production factors to coordinate operation and ensure the efficient operation of enterprises. Uniqueness, value, ductility, durability and integration are important indicators.

\section{B. The identification of core competence}

Enterprise capability survey is the premise to identify core competence. We should first summarize the "ability list" with the ability of the enterprise, and then select according to the following principles:

(1) Whether it can effectively provide the module products or final products that meet the needs of consumers.

(2) Whether the product and service value maximization and consumer utility maximization can be realized.

(3) Can be unique and difficult to imitate. By following these principles, we can take market research, enterprise capability internal investigation and other methods to identify the core capabilities, and take the expert grading method, AHP analysis and so on to judge the recognition results.

When identifying core competencies, an enterprise should include the following:

(1) Technology. Scalable, hard-to-copy technologies are fundamental to core competencies, and core competencies are integrated with a number of technologies that have production attributes or very productive attributes.

(2) Tradition. Tradition is similar to history, and corporate history is unique and difficult to replicate.

(3) Relationship. Relationships refer to internal and external relationships between business and senior management, employees, suppliers, and customers [2].

\section{The cultivation of enterprise core competence}

\section{1) Organizational learning}

The cultivation of core competence is the process of organizational learning. quoting Rafael Andreeu and Claudio Ciborra (1998) a three-stage learning model of the core capacity, which includes programmatic learning, ability learning, and strategic learning three levels [3]. Procedural learning requires the optimization of goals and organization's performance within the scope, including the efficient access to external information, the absorption of internal technology knowledge, the promotion of organizational protocol understanding; Ability learning requires the use of existing organizational resources to realize effective processing of information knowledge, which can effectively synthesize external knowledge and effectively activate internal knowledge. 
Strategic learning requires enterprises to adapt to the environment and obtain information knowledge. The ultimate goal is to establish the development direction consistent with the enterprise's mission, resources and competitive environment, and to extract the core competence of the enterprise.

\section{2) Self-development and cooperation innovation}

Self-development and cooperative innovation are important tools for cultivating core competencies. As a technological complex, an enterprise should promptly develop its core competence through self-research and cooperative innovation in accordance with changes in the external environment and internal resource conditions, combined with technological innovation cycles.

\section{3) Mergers and acquisitions}

Mergers and acquisitions are also an important means of nurturing core competencies. Although mergers and acquisitions and acquired parties are different in terms of corporate resources, operational processes and value objectives. They are prone to failures in mergers and acquisitions. However, compared to other means, it has the advantages of reducing risks, acquiring complementary assets and capabilities and being easy and quick to enter new business areas. Esse Ibein Frances et al. (2001) believe that resources, processes and values are the determinants of organizational capability, and determine whether the enterprise can do anything from different perspectives [4]. Resources refer to flexible objects or assets, including manpower, equipment, technology and brand; Process means the transformation of resources into product or service communication, coordination and decision-making processes, and each process is only applicable to specific tasks; Value refers to the criteria on which priority decisions are made. Combining the characteristics of m\&a with the determinants of organizational capability, the company should cultivate the core competence of the enterprise based on resources, value and process. The merger and acquisition party should inject its own resources into its operation process to maximize its value without interfering with the business development of the acquired party. The m\&a party should also actively integrate with the operation process and value goal of the merger in order to realize the Coordinated and unified development of the two resources.

\section{4) Comprehensive innovation management}

Technological innovation, management innovation, process innovation, and mechanism innovation constitute the complex system engineering of enterprises. Among them, technological innovation is the foundation of core competence. Faced with the drastic changes in the market environment, only by relying on technological innovation and conducting comprehensive enterprise innovation management can companies accurately position and effectively nurture core competencies. Comprehensive innovation management has four levels. Firstly, the core competence cultivation shall be through the company team, operation process and individual employee, and be based on the unique corporate culture and enhance the continuous competitive advantage. Secondly, we have implemented a total of strategic innovation, management innovation, technological innovation, corporate culture, organizational structure innovation and business process innovation, and we have really implemented a full coverage of innovation-management enterprise. Thirdly, we should effectively coordinate the development strategy, business process, composition personnel and corporate performance, and benefit the stakeholders. Finally, the enterprise should fully, full-time, the entire process involved in innovation, and then actively integrate resources into the comprehensive innovation management which is centered on technological innovation.

\section{The ANAlysis of TCl's CORE POWER BREEDING MODE}

China has become a "double crown" for color TV production and consumption, which is characterized by fierce price competition and high degree of marketization. However, 'large and not strong' has always been the disease of China's color TV industry. But that is starting to change, with TCL making the world's third-largest and China's largest by 2020, according to a report by IHS MARKIT, a leading global market research firm. This is the first time that Chinese brands have crossed the threshold of 20 million and become the first group in the world. It is a proof of the positive effect of TCL's core competence in science and technology, which has proved that China has been making a real progress towards 'color TV power' after years of efforts.

\section{A. The development of TCL's core competence}

In 1992, TCL group invested 20 million yuan to set up and enter the color TV industry, and took the OEM operation mode. After more than 20 years of core competence exploration and cultivation, it finally became a commercial giant of domestic color TV industry in 2016 and enjoys a worldwide reputation.

In the early 1990s, when TCL walked into the market, there were almost 100 production lines and dozens of color TVS, but the small screen TVS were the main product of these manufacturers, and only a few of them had big screen color technology. Technical limitations of domestic color TV manufacturers to provide an opportunity for imported color television bully occupy the Chinese market, almost four 5 of the domestic market share is occupied.

In 1992, TCL seized the market opportunity of large-screen color TV demand and adopted a business model that imported large-screen color TV parts from abroad and sold them at a price less than $30 \%$ to $80 \%$ of the domestic similar products, so that TCL could be fired in the color TV industry. In addition, TCL has actively cooperated with domestic and foreign color TV companies to expand the domestic market rapidly with the help of panda color TV production equipment, Great Wall color TV financing and technology, using its own brand effect and domestic marketing network. In 1998, TCL's exclusive color TV base was completed in Huizhou, with the advanced level as reference for the base planning design and technological innovation upgrading, and the annual production volume reached 3 million and increased year by year. In 2000, it established TCL digital technology and expanded its business scope with Wuxi electric instrument asset management co., LTD. In 2002, it acquired Germany Schneider electric co., ltd. and successfully developed the sales channels of color TV in Europe. In November 2003, TCL and French consumer 
electronics giant Thomson signed a letter of intent for the merger and reorganization of the color TV and DVD businesses, and set up a joint venture with its television business to establish a new company. In 2004, TCL color TV sales surged and broke through the 1,000-yuan mark, with a total of 17.16 million domestic and foreign sales for the year.

Then TCL went into high speed development, and actively explore cultivating core ability, today has grown into the domestic international flagship enterprise with good reputation sales channels.

\section{B. The way to cultivate the core competence of TCL color TV}

1) Creative imitation and the attention paid to the interests of the latter

In the face of high-speed technological innovations, the equipment and technology that have been phased out by startup companies are beneficial to the development of latecomers. If the latecomers can efficiently use and innovate to eliminate resources, they can achieve transcendence in their learning and use, thus occupying a favorable competitive position.

The opportunity for TCL to get into the color power industry was a scientific prediction of the soaring demand of the Chinese market. It was based on the need to work with the enterprise and to do creative imitations, which was the foundation for the innovation and the business model of the enterprise's own manufacturing process. After successfully entering the domestic market, it started to get rid of foreign aid and build the exclusive production base of the enterprise. It introduced advanced technology and equipment from foreign countries to improve the hardware level of enterprises and implemented low-cost production strategies. Under the condition of excellent hardware resources, it sought to joint venture with foreign influential enterprises. What's more, it have carried out technical exchange and learning, introduced the production and management methods of Japanese and Japanese enterprises systematically, implemented comprehensive quality management, and improved efficiency and efficiency.

\section{2) High-speed replication of operational capabilities}

Since the completion of the first production base in 1998, five production bases have been established in the late 20th century. Based on the successful operation of Huizhou production base, the operation capacity of production process, personnel management and incentive mechanism was actively copied. Successfully realized the operation of several production bases, and formed great competitiveness in terms of quantity, quality and cost of products [5].

3) The successful implementation of the cost leadership strategy for high-end products

The leading edge of China's manufacture in the world is low cost manufacturing. However, many domestic enterprises have not successfully applied the cost leadership strategy and positioned the product at the low end and fought a price war, thus gradually losing their profitability and getting into a development dilemma. TCL color electric operates the business objective of 'high quality and low price', so as to realize low price with technological innovation and cut directly into the high end product market, which is extremely competitive with competitors. When entering the color TV market, TCL color TV purchased parts from abroad to produce large screen color TV and sold at least $30 \%$ of the other products in China, avoiding the price war and gaining market share and high profit for the enterprise.

4) Positive development of brand reputation and business ability

In 2004, the value of TCL brand was the highest in China's color TV industry. In recent years, it has been the first brand of domestic color television. The high cost performance is its brand characteristic. It also dedicates to enhance the brand awareness and create a good reputation with scientific and technological innovation. In addition, TCL is actively expanding, with over $20 \mathrm{r} \& d$ facilities and manufacturing facilities in the world, selling agencies and businesses in hundreds of countries and regions, creating an international distribution network of operations, and marketing through direct marketing models. It also focuses on integrating internal and external resources. It pays attention to its own technological innovation and the joint venture cooperation between domestic and foreign enterprises, so as to fully realize the sharing of advantageous resources. In this way, they can further expand our business capacity.

\section{CONCLUSION}

The discussion on the fundamental issues of the survival and development of enterprises are key issues that the academic community and the industry are concerned about. The concept of the core competence of the enterprise solves the problem of the source of the enterprise's lasting competitive advantage [6]. This study has drawn the following conclusions: First, core competencies are the essence of corporate competition, and they are the knowledge systems that have been formed and accumulated during long-term development. They can adapt to and make use of the external environment, and can effectively integrate internal and external corporate resources. The identification of enterprise core competence is a prerequisite for cultivation. Based on the principles of practicality, utility, and uniqueness, a variety of identification methods are used to sum up the "capacity list"; Third, the cultivation of core competences of TCL's color TV sets will provide a breakthrough for the company. The development shows that the core competence plays an important role in the growth and development of the company. With the increasingly perfect market economy, Chinese enterprises will enter the stage of competition for core competences. 


\section{REFERENCES}

[1] [MAO wuxing, yan tongzhu, liu jingjiang, xu qingrui. Cultivation and improvement of core competence of Chinese enterprises: strategy, path and case study [J]. Scientific research management, 2004(02):37-43.

[2] Yuan zepei. Identification and cultivation of the core competence of enterprises [J]. Jianghan BBS, 2002(01):34-36.

[3] Rafael Andreu , Claudio Ciborra (1998).Organizational Learning and Core Capabilities Dvelopment:the Role of IT.Information Technology and organizational Transformation .Edited by $\mathrm{R}[\mathrm{M}]$.Galliers and W.R.J .Baet s ,John Wiley \&Sons Ltd.

[4] Hesselbein Frances, Goldsmith Marshall, Somerville Iain (2001) Leading for Innovation and Organizing for Results Jossey -Bass [M].

[5] Yu renqiao, zhang tao. Discussion on the core competence cultivation model of China's post-development enterprises-taking TCL's flagship color TV as an example $[\mathrm{J}]$. Scientific and technological progress and countermeasures, 2005 (10):170-172.2005(10):170-172.

[6] Wang Yi. Empirical Research on the Core Competence of Chinese Enterprises [J]. Journal of Management Science, 2002(05): 74-82. 